\title{
Carcinoid tumor arising in a mature cystic teratoma: A case report
}

\author{
ZEYNEP TOSUNER $^{1}$, FATMA CAVIDE SÖNMEZ ${ }^{1}$, DILEK SEMA ARICI ${ }^{1}$ and RAMAZAN DANSUK ${ }^{2}$
}

Departments of ${ }^{1}$ Pathology and ${ }^{2}$ Gynecology, Faculty of Medicine, Bezmialem Vakıf University, Istanbul, Fatih 34093, Turkey

Received July 1, 2014; Accepted February 2, 2015

DOI: $10.3892 / 01.2015 .2998$

\begin{abstract}
Mature cystic teratomas are common benign tumors of the ovary. The most common form of malignant transformation is squamous cell carcinoma, however, malignant transformation is rarely observed and cases are usually asymptomatic. Carcinoid tumors are rare tumors of the neuroendocrine system. A number of the carcinoids result in clinical syndromes due to the secretion of vasoactive substances produced by the tumor. A 75-year-old woman suffering from groin pain was admitted to the Faculty of Medicine at Bezmialem Vakıf University (Istanbul, Turkey). An adnexal mass was detected during the physical examination. Magnetic resonance imaging scans exhibited an 8x7-cm mass in the right ovary. Surgical excision of the mass was performed and histopathological examination revealed a mature cystic teratoma with three germ layers. An area consisting of nests and trabeculae was evident in the cyst wall. The pathological diagnosis was of an insular and trabecular variant of carcinoid tumor arising in a mature cystic teratoma. The patient did not present with carcinoid syndrome, and no recurrence was observed after 11 months of follow-up examinations.
\end{abstract}

\section{Introduction}

Mature cystic teratomas are benign unilateral tumors often diagnosed in young females. Teratomas are composed of tissues derived from the three germ layers; ectoderm, mesoderm and endoderm (1). The most common sites of occurrence are the sacrococcygeal region and the ovaries (2). A malignant tumor that arises in a pre-existing mature teratoma is called teratoma with malignant transformation (3). Malignant transformation occurs in $1-3 \%$ of all mature teratomas (4). Squamous cell carcinoma is the most common form of transformation (5). Transformation into other types of tumor, including thyroid carcinoma, adenocarcinoma and carcinoid tumor, has also been reported $(5,6)$. Carcinoid tumors are slow-growing tumors, originating from neuroendocrine cells, which are classified

Correspondence to: Dr Zeynep Tosuner, Department of Pathology, Faculty of Medicine, Bezmialem Vakıf University, Vatan Street, Istanbul, Fatih 34093, Turkey

E-mail: zeyneptosuner@yahoo.com.tr

Key words: carcinoid, teratoma, ovary into four categories: i) Insular; ii) trabecular; iii) strumal; and iv) mucinous types $(7,8)$. Carcinoids are most commonly found in the ileum and appendix. While mature cystic teratomas are benign tumors, carcinoid tumors of the ovary are considered to be malignant and are occasionally associated with metastases $(7,8)$. In previous studies, the majority of carcinoid cases of the ovary were associated with carcinoid syndrome, which leads to symptoms such as, cutaneous flushing, diarrhea, bronchoconstruction and right-sided cardiac valve disease (9-11). Carcinoid tumours have variable clinical behaviour. While they are considered to be slow growing, a metastatic disease is often stated on the initial presentation of carcinoids (12). The overall 5-year survival rate for patients with carcinoids regardless of location is $44-56 \%$ (13). The presence of regional and distant metastases are associated with a worsening in the prognosis. Hormone and vasoactive amine secretion from the carcinoid tumor cells cause carcinoid syndrome. Serotonine, tachykinine, prostaglandines and histamine are the main secretions of carcinoids. The secretion of these substances cause symptoms as flushing, diarrhea, bronchial obstruction and heart failure (14). Surgery is the main treatment for carcinoid tumors and previous cases of carcinoids arising in mature teratomas of the retroperitoneum and ovary, which were successfully treated by surgical resection have been reported in the literature (15-17). The current study describes an insular and trabecular variant of carcinoid tumor arising in a mature cystic teratoma, which is notable due to the rarity of this occurrence. This study was approved by the ethics committee of Bezmialem Vakıf University (Istanbul, Turkey) and written informed consent was obtained from the patient.

\section{Case report}

A 75-year-old woman (gravidity $=6$, parity $=6$, curettage $=3$ ) suffering from groin pain was referred to the gynecology clinic at the Faculty of Medicine, Bezmialem Vakıf University in August 2013. An adnexal mass was located during the physical examination. Pelvic magnetic resonance imaging revealed an $8 \times 7-\mathrm{cm}$ mass in the right ovary, compatible with a dermoid cyst. The patient was postmenopausal for 30 years, had undergone cholecystectomy 14 years prior and appendectomy 57 years prior. The tumor markers were negative and right salpingo-oophorectomy was performed.

Macroscopic examination revealed a cystic mass filled with viscous sebaceous material, measuring $10 \times 9.5 \times 8 \mathrm{~cm}$. The cyst wall also contained bony structures, which indicated a teratomatous origin. Multiple samples were obtained from the 

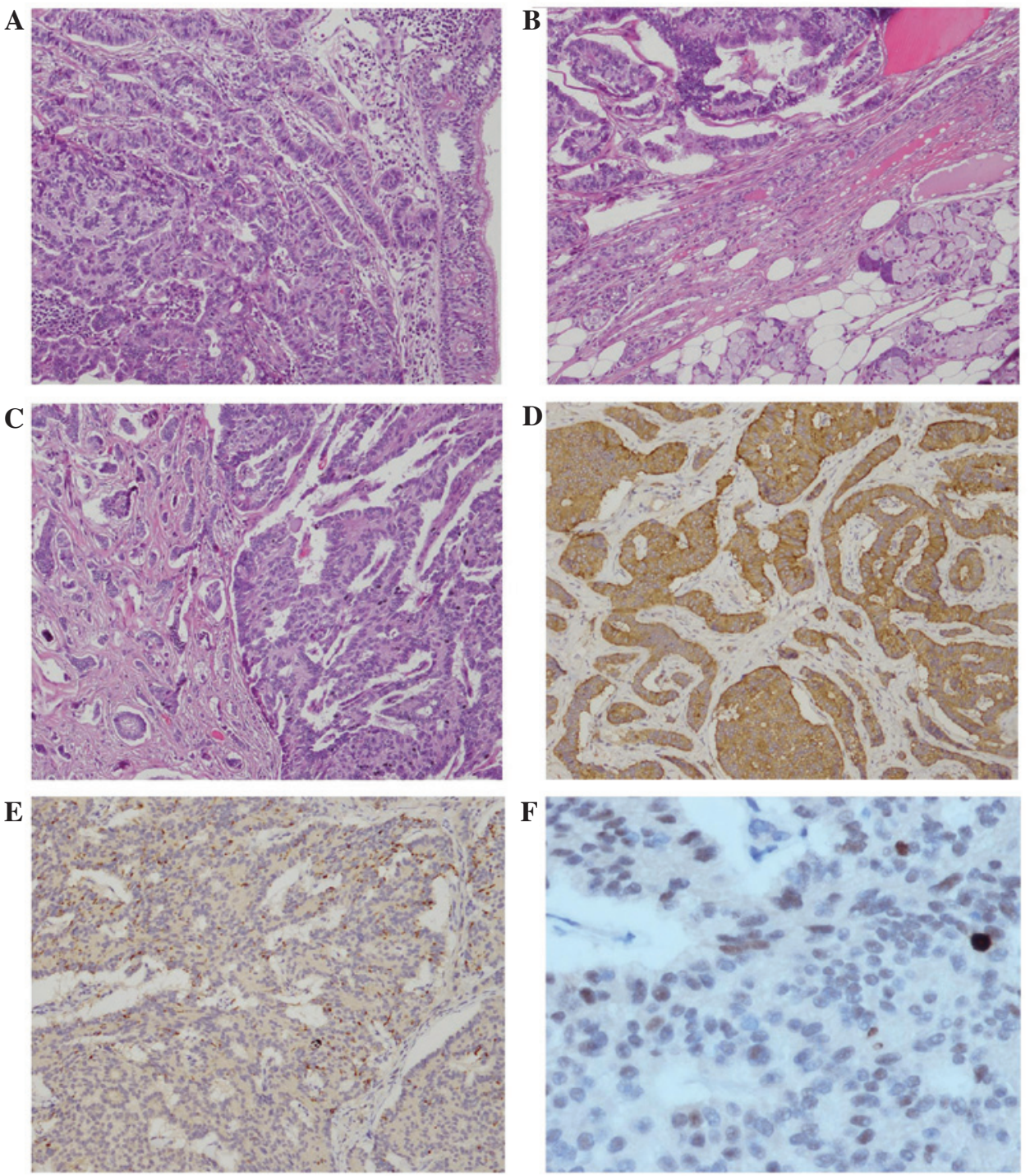

Figure 1. Hematoxylin and eosin staining of (A) respiratory epithelium on the surface, nests and cords of neoplastic cells in the cyst wall; (B) trabecular structures of carcinoid, mucous glands and fibroadipous tissue in teratoma; and (C) neoplastic cells forming nests and trabeculae. Magnification, x100. (D) Diffuse intense immunoreactivity of synaptophysin (magnification, x100); (E) diffuse immunoreactivity of chromogranin (magnification, x100); and (F) proliferative activity assessed by Ki-67 (magnification, $\mathrm{x} 400)$.

specimen and evaluated. On the histological sections, mature squamous and respiratory epithelium and mature mesenchymal components were identified. The cyst wall contained a $4.5-\mathrm{mm}^{2}$ area consisting of neoplastic cells forming nests, cords and trabeculae. The neoplastic cells were uniform, with small round nuclei without atypia or mitotic activity, as observed by hematoxylin and eosin staining in Fig. 1A-C.

Immunohistochemical staining, including synaptophysin, chromogranin and Ki-67 were applied. Diffuse intense immunoreactivity of synaptophysin (Fig. 1D) and chromogranin (Fig. 1E) was present, indicating that the tumor was of neuroendocrine origin. The proliferation index was determined by Ki-67 expression and was $2 \%$ (Fig. 1F). Thus, the tumor was classified as low grade (18). Morphological and immunohistochemical findings indicated a carcinoid tumor arising in the wall of the mature cystic teratoma.

The patient received no further treatment, and no recurrence was observed after 11 months of follow-up examinations.

\section{Discussion}

Malignant transformation is a rare complication of mature cystic teratomas (19). Carcinoid tumors are rare and have been presented as case reports previously $(20,21)$. Carcinoid tumors in ovarian and testicular teratomas are considered to be derived from neuroendocrine cells of the gastrointestinal or respiratory epithelium $(17,22)$. In the present case, the carcinoid tumor was located near respiratory epithelium. Serotonin, histamine, catecholamines, prostaglandin and vasoactive peptides are frequently secreted by carcinoid tumors predisposing affected patients to carcinoid syndrome. However, the patient in the current case study did not present with carcinoid syndrome. Carcinoid tumors arising from teratomas have been reported in postmenopausal cases in previous case reports $(6,23)$. The patient in the present report was also postmenopausal. Cyst wall invasion, intraoperative rupture of the cyst and tumor seeding are defined as poor prognostic factors in malignant transformation of 
teratomas (24). Carcinoid tumors arising in mature teratomas are tumors with low malignancy potential (17). However, the prognosis and clinical behavior of these tumors have not yet been clarified (25). Without resection of the tumor, the risk of malignant transformation increases with time. All suspected areas in the cyst walls should be sampled in order to define these unusual rare neoplasms. In the present case report, the tumor was in a small area in the cyst wall and completely resected. This case was notable due to the rarity of this occurrence.

\section{References}

1. Prokhorova TA, Harkness LM, Frandsen U, et al: Teratoma formation by human embryonic stem cells is site dependent and enhanced by the presence of Matrigel. Stem Cells Dev 18: 47-54, 2009.

2. Gatcombe HG, Assikis V, Kooby D and Johnstone PA: Primary retroperitoneal teratomas: a review of the literature. J Surg Oncol 86:107-113, 2004.

3. Harms D, Zahn S, Göbel U and Schneider DT: Pathology and molecular biology of teratomas in childhood and adolescence. Klin Padiatr 218: 296-302, 2006.

4. Stamp GW and McConnell EM: Malignancy arising in cystic ovarian teratomas. A report of 24 cases. Br J Obstet Gynaecol 90: 671-675, 1983.

5. Hackethal A, Brueggmann D, Bohlmann MK, et al: Squamous-cell carcinoma in mature cystic teratoma of the ovary: systematic review and analysis of published data. Lancet Oncol 9: 1173-1180, 2008.

6. Kim SM, Choi HS, Byun JS, et al: Mucinous adenocarcinoma and strumal carcinoid tumor arising in one mature cystic teratoma of the ovary with synchronous cervical cancer. J Obstet Gynaecol Res 29: 28-32, 2003.

7. Kurman RJ, Hedrick Ellenson L and Ronnett BM (eds): Blaustein's Pathology of the Female Genital Tract. 6th Edition. Springer, New York, NY, pp883, 2011.

8. Robboy SJ, Mutter GL, Prat J,et al: Robboy's Pathology of the Female Reproductive Tract. 2nd Edition. Churchill Livingstone, London, UK, pp761-765, 2009.

9. Davis KP, Hartmann LK, Keeney GL and Shapiro H: Primary ovarian carcinoid tumors. Gynecol Oncol 61: 259-265, 1996.

10. Robboy SJ, Norris HJ and Scully RE: Insular carcinoid primary in the ovary: a clinicopathologic analysis of 48 cases. Cancer 36 : 404-418, 1975.

11. Soga J, Osaka M and Yakawa Y: Carcinoids of the ovary: an analysis of 329 reported cases. J Exp Clin Cancer Res 19: 271-280, 2000.
12. Druce MR, Lewington V and Grossman AB: Targeted radionuclide therapy for neuroendocrine tumours: principles and application. Neuroendocrinology 91: 1-15, 2010.

13. Modlin IM and Sandor A: An analysis of 8305 cases of carcinoid tumors. Cancer 79: 813-829, 1997.

14. Norheim I, Oberg K, Theodorsson-Norheim E, et al: Malignant carcinoid tumors. An analysis of 103 patients with regard to tumor localization, hormone production, and survival. Ann Surg 206: 115-125, 1987.

15. Shindo K, Ueda J, Toubo T, Nakamura M, Oda Y, Eguchi T and Tanaka M: Primary carcinoid tumor in a retroperitoneal mature teratoma: report of a case: Surg Today 43: 694-697, 2013.

16. Guney N, Sayilgan T, Derin D and Ozcan D: Primary carcinoid tumor arising in a mature cystic teratoma of the ovary: a case report: Eur J Gynaecol Oncol 30: 223-225, 2009.

17. Yamasaki T, Yagihashi Y, Shirahase T, Hashimura T and Watanabe C: Primary carcinoid tumor arising in a retroperitoneal mature teratoma in an adult: Int J Urol 11: 912-915, 2004.

18. Klimstra DS, Modlin IR, Coppola D, Lloyd RV and Suster S: The pathologic classification of neuroendocrine tumors: a review of nomenclature, grading, and staging systems. Pancreas 39: 707-712, 2010.

19. Donadio AC, Motzer RJ, Bajorin DF, Kantoff PW, Sheinfeld J, Houldsworth J, Chaganti RS and Bosl GJ: Chemotherapy for teratoma with malignant transformation. J Clin Oncol 21: 4285-4291, 2003.

20. Flam F and Silfverswärd C: Combination of granulosa cell tumour and carcinoid in an imitation of appendix vermicularis within a mature teratoma - a unique case. Eur J Obstet Gynecol Reprod Biol 56: 139-142, 1994.

21. Chatzipantelis P, Mavrogiorgis A, Kairi-Vassilatou E and Pafiti A: Ovarian neoplasm composed of an insular carcinoid tumor and a borderline mucinous cystadenoma arising in a mature cystic teratoma: a case report. Eur J Gynaecol Oncol 27: 636-637, 2006.

22. Sens MA, Levenson TB and Metcalf JS: A case of metastatic carcinoid arising in an ovarian teratoma. Case report with autopsy findings and review of the literature. Cancer 49: 2541-2546, 1982.

23. Thorson A, Hanson A, Pernow B, et al: Carcinoid tumour within an ovarian teratoma in a patient with the carcinoid syndrome (carcinoidosis); clinical picture and metabolic studies before and after total resection of tumour. Acta Med Scand 161: 495-505, 1958.

24. Arora DS and Haldane S: Carcinosarcoma arising in a dermoid cyst of the ovary. J Clin Pathol 49: 519-521, 1996.

25. Isobe H, Takashima H, Higashi N, Murakami Y, Fujita K, Hanazawa K, Fujime M and Matsumoto T: Primary carcinoid tumor in a horseshoe kidney. Int J Urol 7: 184-188, 2000. 